\title{
Identifying Plant Poisoning in Livestock
}

\section{By Bryan L. Stegelmeier, Benedict T. Green, Kip E. Panter, Kevin D. Welch, and Jeffrey O. Hall}

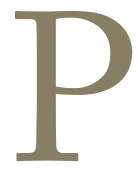

oisonous plant intoxication is a common and often deadly problem costing the western livestock industry in the United States more than $\$ 340$ million every year. Despite the costs and high frequency of occurrence, arriving at a positive diagnosis of plant poisoning in livestock is challenging. The purpose of this paper is to provide a framework to help range professionals make an accurate, or definitive, diagnosis. We provide suggestions for investigating and sampling field cases of suspected plant poisoning, and for integrating important information.

An essential part of making an accurate diagnosis is obtaining and understanding the animals, location, plant communities involved, and management strategies being used (Table 1). Compiling animal information such as type and condition of animals, age, sex, nutritional status, and vaccination history as well as identifying clinical signs, lesions, number of affected animals, and progression of disease are the first steps in identifying a cause. These findings are critical because they will be used to direct the investigation. This background information should be included with all samples collected and when submitting samples to your veterinarian or diagnostician. This information is essential to all involved in helping make an accurate diagnosis.

Once this information is gathered, a list of potential causes called a "differential diagnosis" should be developed. This list will be used to develop an investigative plan that will focus on confirming the right diagnosis and excluding all other possibilities. Making a complete and thorough list will require engaging appropriate experts (Table 2). The local veterinarian is a key player in this process. Many infectious, degenerative, and immunologic diseases produce clinical signs, biochemical changes, and lesions identical to those caused by toxins and poisonous plants. Local veterinarians will be familiar with disease conditions that occur in the area. He or she will also know other local or state experts, such as toxicologists, diagnosticians, or pathologists, who might contribute to the diagnostic process. The differential diagnosis list should be as complete as possible so that appropriate tests can be used to confirm the cause of the clinical syndrome.

The next step is to use the list of differential diagnoses to formulate a plan to rule out or confirm possible causes. The plan will probably include field investigations, physical examinations, biochemical or serologic evaluations of the blood, possible postmortem evaluations, and, at times, chemical or microscopic evaluations of plants or animal tissues.

\section{Field Investigations}

Field studies are an essential part of most investigations and should be conducted early in the diagnostic process. You may want to seek out experts who might contribute to these studies, including extension agents and local or state veterinarians. The list of differential diagnoses should include a short list of plants that might produce the clinical symptoms observed. Many county extension agents are trained in plant identification, or they can be very helpful in finding outside experts (Table 2). Close examination of pastures and ranges should include a determination of what plants are present in the community and what plants the animals are eating. Plants that were included in the list of differential diagnoses or unidentified plants should be collected for positive identification. Plant samples are best collected in paper bags. If plant samples are to be mailed to the local herbarium or the Poisonous Plant Research Laboratory, they should be pressed and dried. The entire plant should be collected if possible. Flowering plants are most easily identified. A convenient way to press plants is to place them between two pages of a newspaper and press them under a couple of heavy books for several days. Pressed plants may be mailed in a large envelope taped to a sheet of cardboard. Most state land grant or agricultural colleges have herbaria with experts able to identify most plants. The Poisonous Plant Research Laboratory, in collaboration with the Intermountain Herbarium at Utah State University, has taxonomic capabilities if local options are unavailable.

Since the toxicity of a plant is often variable, additional plant samples may be needed for a chemical evaluation of potential toxins. It is best to label carefully and freeze freshly collected plant samples in plastic bags if the samples are to 


\section{Table 1. Components essential for a good diagnosis in suspected plant poisoning episodes}

History and clinical disease:

Pertinent facts: breed, sex, age, number, condition, vaccination status, mineral supplements, feeding or pasture changes, and other treatments

Clinical disease: number affected, signs, clinical course and progression, lesions, and mortality

Clinical tests: blood tests to evaluate inflammation and organ function, and to evaluate immunologic responses to infectious agents (blood cell counts and serum element, metabolite and biochemical analyses, and serologic tests)

Field studies:

Animals: condition, unusual behaviors, clinical signs, and lesions. Additional clinical tests may be indicated: blood tests or chemical tests for plant toxins or metabolites in the tissues, blood, urine, or feces

Pasture:

1) Determine forage availability, plant species composition, and evidence of grazing patterns

2) Collection of potential problem plants or unidentified plants (dried samples for identification, frozen samples for chemical analysis)

3) Note weather conditions and their effect on forage and forage availability

Prepared feeds: hay, silage, or concentrate feed samples (frozen for analysis)

Water, salt, and mineral supplements including location and use (samples frozen for analysis)

Physical location, weather at time of incident, and other obstacles

Check for other potential hazards, such as old batteries and pesticide-laced feed

Postmortem examination:

Animal condition and lesions

Rumen and gastrointestinal tissues and contents

Tissues for histologic studies fixed in $10 \%$ neutral buffered formalin (brain, lung, heart, liver, spleen, gastrointestinal tract, kidney, skeletal muscle, and any gross lesions)

Tissues for chemical or microscopic studies stored in plastic bags and frozen (rumen and gastrointestinal contents, feces [from live animal], complete eye, liver, kidney, serum, whole blood, body fat, bone, urine, milk if lactating). Whole blood for blood cell evaluation should not be frozen

be analyzed chemically. Care should be taken to ensure the samples remain frozen during shipping. If freezing is not an option, partially drying the plant by placing it in a paper $\mathrm{bag}$, then drying the bagged plant in an oven at $150^{\circ} \mathrm{F}$ $\left(65^{\circ} \mathrm{C}\right)$ for 12 hours will preserve the sample until it can be analyzed. Do not microwave plant samples. Refrigerated plants generally become moldy and rot; moldy samples are of little use for plant identification or chemical analysis. Because each laboratory has specific submission requirements, it is best to contact the laboratory prior to submission to ensure the sample is properly prepared and that an adequate sample size is being sent (Tables 2 and 3).

Some field studies may include evaluation of prepared feeds or forages. Identifying toxic plants in hay is possible, but often problematic. Poisonous plant contaminants in harvested feeds are generally not distributed uniformly, so proper sampling is critical. Most poisonous plants grow in patches, and so often only a few bales from an entire field are contaminated. Additionally some symptoms of toxic plant ingestion are not manifested for days or even months later. During the delay between ingestion and the display of symptoms, the contaminated feed may have been consumed, making it unavailable for sampling. Consequently it is often more productive to examine the area where the feed was harvested. Close examination of the hay field especially prior to cutting the first crop provides a better indication of contamination than trying to find patches of plants postharvest. Thorough sampling of hay should include many bales (at least five or six) to maximize the chance of finding contaminating plants. Core samples of hay are often used for nitrate or chemical analysis, but they destroy plant morphology and therefore are of minimal use for plant identification. When more intensely prepared feed, such as pellets, are submitted for analyses, they should be randomly sampled, dried at low temperatures, and stored in paper bags so that they do not mold.

Good field studies also include close monitoring and examination of the animals. Livestock producers and 


\begin{tabular}{l} 
Table 2. Resource list \\
\hline USDA/ARS Poisonous Plant Research Laboratory: \\
1-435-752-2941 \\
http://www.pprl.ars.usda.gov \\
State agricultural extension service: \\
http://www.csrees.usda.gov/Extension \\
State animal disease diagnostic laboratory: \\
Contact your local or state veterinarian \\
http://www.aavld.org/mc/page.do?sitePageld=33930. \\
Id=aavld (laboratories accredited by American \\
Association of Veterinary Diagnostic Laboratories) \\
Local herbarium \\
Contact your local county agent or land grant college \\
or university \\
http://herba.msu.ru/mirrors/www.helsinki.fi/kmus/ \\
botmus.html (lists of public herbaria throughout the \\
world) \\
Microscopic analysis of feces and ingesta \\
Texas Veterinary Medical Diagnostic Laboratories \\
1-888-646-5623 \\
http://tvmdlweb.tamu.edu
\end{tabular}

herders have the most contact with the animals, and so they are generally able better to observe subtle changes that often occur in poisoned animals. It is essential that they communicate those changes to extension agents and veterinarians. A good diagnostician or veterinarian will use this information with the clinical signs to formulate an initial clinical diagnosis. Observations from experienced observers are valuable for clinical studies because many toxic plants produce subtle changes that are obvious to the alert observer. For example, locoweed poisoning often produces characteristic "dull" appearing eyes, whereas larkspur poisoning may result in failure to defecate completely.

Important information can also be obtained from sick animals. Blood or serum biochemical and serologic studies can help rule out infectious diseases. For example, many inflammatory bacterial or viral diseases produce characteristic changes in circulating white blood cells. Blood cell counts and white blood cell evaluations are very helpful in eliminating these diseases from the list of differential diagnoses. Some plant toxins produce characteristic damage to specific organ systems. Biochemical analysis of blood or serum for metabolites or enzyme activities can be useful in identifying damaged tissues. For example, damaged livers typically result in increased serum activities of specific enzymes. These enzymes differ from those that increase with muscle damage. Other diseases such as kidney disease cause increased concentrations of specific metabolites such as urea. Such biochemical changes are useful to identify damaged tissues and ultimately support a specific diagnosis.
It can often seem that the best and most expensive animals are the first to be poisoned and die. If these fatalities are detected early and used to prevent further losses, these animals truly are the most valuable in the herd. A good postmortem examination, or necropsy, provides the most information needed to formulate a definitive diagnosis. Field necropsies are essential in many investigations. The best and most diagnostic samples are obtained from animals that have recently died, or dying animals that are euthanized just prior to necropsy. Rotten carcasses provide little information because some toxins degrade and the tissues become unsuitable for microscopic evaluation. Many veterinarians have a great deal of experience with necropsies and are adept at identifying lesions and tissues damaged by plant toxins. When possible, submitting freshly dead or moribund animals to a diagnostic laboratory can increase diagnostic speed and accuracy. Nearly all states have animal diagnostic laboratories that specialize in postmortem examinations and diagnosing animal diseases. These services are usually supported by state agriculture departments with most fees being minimal. The veterinary pathologists at these facilities have the experience and instrumentation to recognize, sample, and analyze postmortem tissue samples (Table 2).

At necropsy (either a field necropsy or one performed in a diagnostic laboratory), animal tissue samples are collected for microscopic studies (Table 1). These tissues should be small $(0.5 \times 0.5 \times 1.0$ inches $)$ and preserved in fixative $(10 \%$ neutral buffered formalin with volumes of about 10 times the volume of the tissues). Microscopic evaluation of animal tissues is essential in identifying many plant-induced lesions. However, most of the plant-induced microscopic lesions are not specific for plant toxins. For example, halogeton forms oxalate crystals that damage kidney cells. There are other diseases and substances, such as antifreeze, that can produce similar crystals. However, in sheep that are eating halogeton (not drinking antifreeze), such crystal-induced kidney disease is highly diagnostic. If there are no microscopic lesions or if information from microscopic studies does not specifically identify the cause, the results can always be used to narrow the list of possible diagnoses. For example, many infectious diseases cause characteristic microscopic lesions, and the absence of these lesions generally indicates that such causes can be excluded.

At necropsy, gastrointestinal samples should be collected for physical, microscopic, and chemical evaluations. Many plants have characteristic leaves or cellular structures that can be recognized in the rumen or lower intestines. For example, yew or oleander leaves can often be found in the rumen of animals that die of poisoning. Other plants can be identified using microscopic analysis of rumen or gastrointestinal contents. Microscopic evaluation of ingesta for plant identification is a highly specialized field, and samples must generally be sent to laboratories that support such analysis. The Texas Veterinary Medical Diagnostic Laboratory provides a service in which they identify plants in rumen 
Table 3. Partial list of tests, samples, sample size, and preservation for investigation of potential poisonous plant poisoning. Be sure to check with the laboratory because they often require specific sampling, sample preparation, and shipping instructions. Label all materials with indelible ink; provide date, owner, location and contact information

\begin{tabular}{|c|c|c|c|}
\hline Test & Sample & Size & Shipping \\
\hline Blood counts & Purple top blood tube & $3-5 \mathrm{~mL}$ & Chilled on ice \\
\hline Serum biochemistries & Red top blood tube & $5-10 \mathrm{~mL}$ & $\begin{array}{l}\text { Chilled on ice, or if } \\
\text { frozen, serum should be } \\
\text { separated from the cells }\end{array}$ \\
\hline $\begin{array}{l}\text { Microscopic evaluation of } \\
\text { tissues }\end{array}$ & $\begin{array}{l}\text { Various tissues (see } \\
\text { Table 1) }\end{array}$ & $1 \times 1 \times 2$ inch pieces & Fixed formalin \\
\hline Postmortem or necropsy & Dead or moribund animal & Whole animal & Fresh \\
\hline $\begin{array}{l}\text { Chemical evaluation of } \\
\text { serum, blood, urine, or milk }\end{array}$ & $\begin{array}{l}\text { Serum, whole blood, } \\
\text { urine, or milk }\end{array}$ & $20 \mathrm{~mL}$ & $\begin{array}{l}\text { Stored in plastic tubes } \\
\text { and on ice or frozen }\end{array}$ \\
\hline $\begin{array}{l}\text { Chemical evaluation of } \\
\text { tissue }\end{array}$ & Various tissues & $2 \times 2 \times 4$ inch pieces & $\begin{array}{l}\text { Stored in plastic bags and } \\
\text { frozen }\end{array}$ \\
\hline $\begin{array}{l}\text { Chemical evaluation of } \\
\text { feces or gastrointestinal } \\
\text { contents }\end{array}$ & Feces or ingesta & $\begin{array}{l}1-2 \text { pounds (about a } \\
\text { sandwich bag full) }\end{array}$ & $\begin{array}{l}\text { Stored in plastic bags and } \\
\text { frozen }\end{array}$ \\
\hline Plant identification & Whole plant & $\begin{array}{l}\text { Whole plant including } \\
\text { flowers, pods, leaves, } \\
\text { stems, and roots }\end{array}$ & $\begin{array}{l}\text { Fresh if delivered that day, } \\
\text { dried if hand delivered } \\
\text { later, pressed and dried if } \\
\text { shipped }\end{array}$ \\
\hline Plant chemical analysis & Whole plants & 5 or 6 whole plants & $\begin{array}{l}\text { Fresh if delivered that day, } \\
\text { dried if shipped, or frozen } \\
\text { if they can be maintained } \\
\text { frozen during shipping }\end{array}$ \\
\hline $\begin{array}{l}\text { Hay for weed contamination } \\
\text { and weed identification }\end{array}$ & Stored baled hay & 5 or 6 bales & Dry \\
\hline Hay for nitrate analysis & Hay & $\begin{array}{l}\text { Several representative } \\
\text { samples (these can be } \\
\text { core samples), 1-2 } \\
\text { pounds }\end{array}$ & Dry \\
\hline Prepared feeds & Feeds & $\begin{array}{l}\text { Representative feed } \\
\text { samples such as cubed } \\
\text { feed, } 1-2 \text { pounds }\end{array}$ & Dry \\
\hline $\begin{array}{l}\text { Silage or green chopped } \\
\text { feed }\end{array}$ & Feeds & $\begin{array}{l}\text { Representative feed } \\
\text { samples, } 5-10 \text { pounds }\end{array}$ & Frozen \\
\hline
\end{tabular}

or fecal material using microscopic techniques (Table 2). Ingesta, tissues, urine, and blood may also be analyzed chemically for plant toxins. Preservation of samples for chemical analysis should be by freezing of all samples except whole blood, which should be refrigerated. Care should also be taken to ensure frozen samples do not thaw during transport to testing laboratories. Presence of the plant or toxins in the gut provides definitive evidence of consumption but does not prove that the plant caused the poisoning. Because chemical analysis is expensive and specific for particular plant toxins, these assays must be directed and indicated by the clinical and necropsy findings. Screens of animal samples for unknown toxins are most often unproductive because specific instruments and conditions are required to analyze each class of toxin. Generally, chemical analyses for toxins are primarily used to document plant toxicity and confirm poisoning.

Care should be taken in interpreting investigative results to ensure that the clinical disease, postmortem findings, and microscopic findings all support the chemical findings. 
When all information is accumulated and probable diagnoses are evaluated and compared, the diagnostician must integrate this information and determine the most likely diagnosis. This is usually done as the producer, veterinarian, and extension agents consult together and, if possible, include other individuals such as toxicologists, pathologists, and chemists. This can be difficult because some portions of the investigative results may seem contradictory. It is possible that no definitive diagnosis will emerge. Despite the contradictions a most likely diagnosis or short list needs to be made to formulate recommendations and treatment. From these consultations a plan should be formulated to avoid additional poisoning. This step is often relatively easy and inexpensive. For example, livestock poisoning by consuming low larkspur can be averted by delaying turning livestock into the pasture until after low larkspur has begun to senesce. Other solutions may involve changing grazing or animal management, herbicidal control, or a variety of other options.
In summary, correctly organizing, collecting, and preserving materials and enlisting the proper experts and techniques in the correct manner are essential in arriving at accurate diagnoses and formulating practical solutions. A rapid and accurate diagnosis will not only aid in avoiding catastrophic losses, but is also a valuable guide to avoiding future losses to poisonous plants.

Authors are Veterinary Pathologist, bryan.stegelmeier@ars.usda. gov (Stegelmeier), Research Pharmacologist (Green), Reproductive Toxicologist and Research Leader (Panter), and Toxicologist (Welch), Poisonous Plant Research Laboratory, Agricultural Research Service, United States Dept of Agriculture, 1150 E 1400 N, Logan, UT 84341, USA; and Veterinary Toxicologist, Utah Veterinary Diagnostic Laboratory, Utah State University, Logan, UT 84322, USA (Hall). Published with the approval of the Director as Journal Paper No. 8037 of the Utah Agricultural Experiment Station. 